\title{
Exploring mindset's applicability to students' experiences with challenge in transformed college physics courses
}

\author{
Angela J. Little, ${ }^{1, *}$ Bridget Humphrey, ${ }^{2}$ Abigail Green, ${ }^{3}$ Abhilash Nair, ${ }^{1}$ and Vashti Sawtelle ${ }^{3,1}$ \\ ${ }^{1}$ Department of Physics and Astronomy, Michigan State University, East Lansing, Michigan 48823, USA \\ ${ }^{2}$ Department of Neuroscience, Michigan State University, East Lansing, Michigan 48823, USA \\ ${ }^{3}$ Lyman Briggs College, Michigan State University, East Lansing, Michigan 48823, USA
}

(Received 25 April 2018; published 10 May 2019)

\begin{abstract}
The mindset literature is a longstanding area of psychological research focused on beliefs about intelligence, response to challenge, and goals for learning. However, the mindset literature's applicability to the context of college physics has not been widely studied. In this paper we narrow our focus toward students' descriptions of their responses to challenge in college physics. We ask the research question, "can we see responses to challenge in college physics that resemble that of the mindset literature?" In addressing this question, it is also necessary to ask, "how do students express evidence of challenge?" and "to what extent is this evidence similar or different to the mindset literature?" To answer these questions, we developed a novel coding scheme for interview dialogue around college physics challenge and students' responses to it. In this paper we present the development process of our coding scheme. We find that it is possible to see student descriptions of their responses to challenge that resemble the mindset literature's characterizations. However, college physics challenges are frequently different than those studied in the mindset literature. We show that, in the landscape of college physics challenges, mindset beliefs cannot always be considered to be the dominant factor in how students respond to challenge. Broadly, our coding scheme helps the field move beyond broad Likert-scale survey measures of students' mindset beliefs.
\end{abstract}

DOI: 10.1103/PhysRevPhysEducRes.15.010127

\section{INTRODUCTION}

The mindset literature centrally focuses on beliefs about intelligence. If a person believes that it is possible to grow and improve their intelligence or talent, research suggests that this helps them in their educational endeavors and through moments of challenge and failure. Underlying mindset is a sociocognitive theoretical framework. According to this framework, people's experiences with challenge are filtered through their beliefs, making it likely that a person will respond in more or less productive ways [1]. This framework rests on a set of foundational studies that linked beliefs with how children responded to specific challenges.

Mindset is becoming more popular in physics education research in recent years. For instance, at the 2018 American Association of Physics Teachers (AAPT) Summer Meeting, there were seven mindset-related education research presentations [2]. In addition, multiple institutions have been incorporating mindset-related readings and discussions into

\footnotetext{
*littlea7@msu.edu
}

Published by the American Physical Society under the terms of the Creative Commons Attribution 4.0 International license. Further distribution of this work must maintain attribution to the author(s) and the published article's title, journal citation, and DOI. their curriculum [3-6]. However, caution is warranted in how our field adopts mindset-related constructs and methodologies. Only a limited set of challenges have been closely studied in the mindset literature's foundational research. Do these foundational studies apply to the more complicated context of college physics? In this paper, we present key moments and reflections from the development of a novel coding scheme that engages with this concern. We will ultimately raise important questions about the applicability of belief-centric mindset frameworks to transformed college physics courses.

This paper will describe a journey that started with the general research question: "can we see responses to challenge in college physics that resemble that of the mindset literature?" We became interested in this question for a practical purpose: to support the intentional design of physics classrooms that push back on narratives that only some people are good at physics [7]. Our long-term goal is to track students' responses to challenge and then connect those responses to contextual factors in the environment. To begin this work, we focused our efforts on characterizing how students respond to challenge. Our exploration was informed by a context-dependent beliefs theoretical framework [8]. Informed by this framework, we developed interview questions for students at the end of a year of introductory college physics that we expected would yield both growth and fixed mindset-related dialogue. 
Our analysis of these interviews started with the mindset literature's core categories of response to challenge: effort, strategy-use, emotion, and self-capability-related statements. Staying within these core categories, we took the constructs developed for psychological lab contexts and transformed them for use in end-of-semester college physics interview data. In the process of examining students' responses to challenge, it also became necessary to operationalize challenge itself. The mindset literature has taken an approach of exposing children to obvious challenges. For instance, tasks frequently involve logic problems that are multiple grade levels ahead of a child's actual year in school. Our team characterized challenge in the mindset literature and looked to see whether the challenges in our interview data were similar or different. Ultimately, we arrived at two coding schemes: one for "response to challenge" and one for "evidence for challenge."

As our first step was to try out mindset's central constructs, topics such as culture, identity, and equity were not a central focus of this initial work. However, there were multiple points along our process where it became apparent that these topics cannot be ignored. We highlight some of these moments in the paper itself.

Our research program currently involves using these coding schemes in multiple ways. For instance, we are now identifying moments where a single student responds in growth-mindset aligned ways to one challenge and fixedmindset aligned ways to another. Once these key moments are identified, we do an in-depth analysis at both sites.

This paper shares what we have learned from the coding scheme development process itself. Other researchers have argued that important lessons can be learned by sharing and reflecting on the development process of research methodologies $[9,10]$. In this paper we will share some selected methodological moments of how our coding schemes evolved over time. After we present our current coding schemes we will (i) explore differences in the characteristics of challenge across college physics and the mindset literature, and (ii) explore complications to an intelligencebeliefs-related explanation for student responses to challenge in college physics.

\section{A GROUNDING EXAMPLE}

What kind of variation in student dialogue could our coding scheme help uncover? To exemplify one kind of variation, we provide a short excerpt of an interview we performed with a biology major named "Leyla." Leyla is enrolled in a transformed introductory college physics course. Near the end of the course, she compares herself to her peers and deems herself not good at physics: "That's why I think I'm bad at physics. Because it does not, in any way, come easy to me...some of my peers...they'll see a problem, they just know how to do it, and I don't...know how they can do that. It's just so hard for me." This dialogue appears aligned with a fixed mindset: Leyla encounters challenge and makes a negative statement about her ability in physics. Yet, in this same interview, Leyla describes working incredibly hard in response to challenging course and project-based activities. For instance, Leyla notes, "I came in thinking, just, 'I'm going to go to all the office hours, just going to study, do what I need'...I would come into office hours, and I was like, 'Okay. I understand it... I can apply it to any question.' So, I came in not knowing it, and then... Okay, it's really-you see it happening. It's not just on paper." Here, Leyla describes working hard and seeking help through office hours, a description of behavior that is aligned with a growth mindset. Leyla's example shows the importance of not assuming that student dialogue will neatly fit entirely into growth or fixed mindset categories. A student might report that they are "bad at physics," but work hard and be willing to show vulnerability to their instructors in the face of challenge. Our coding scheme for how students respond to challenge will help to concretize what exactly we mean by "aligned" with a growth or fixed mindset.

\section{LITERATURE REVIEW}

Mindset is a longstanding area of psychological research that examines beliefs about intelligence, goals for learning, and responses to challenge. The mindset literature tends to categorize students as having either fixed or growth mindsets: Students with a fixed mindset (FM) "believe that their intelligence is something that is finite and unchangeable. This makes them doubt their intelligence when they experience difficulty and it undermines resilience in learning." In contrast, students with a growth mindset (GM) "believe that intelligence can be developed. In this mindset, students respond more resiliently to challenges and show greater learning and achievement in the face of difficulty" [11]. Growth and fixed mindset are umbrella terms that encompass certain types of beliefs, goals for learning, and responses to challenge. We will sometimes use these umbrella terms to refer to any of these three areas unless a more specific construct is needed for clarity.

Mindset research is vast and encompasses nearly fifty years of scholarship. Summaries of the mindset literature are available $[1,11,12]$. In this paper, we will make an argument that narrowing our focus to understanding how people respond to challenge will provide insight into the applicability of mindset research in college physics. Learning goals, another central aspect of the mindset literature, will not be addressed in this paper as to keep a tighter focus on response to challenge. In this literature review, we first characterize the basic elements of how mindset is traditionally studied. Then, we show that college science, technology, engineering, and math (STEM), particularly college physics, is an understudied area of mindset research. We discuss the relationship between mindset research and equity. We end this section with a description of the theoretical frameworks around 
epistemology in college physics that informed our methodological development.

\section{A. Methodologies of mindset research}

To measure beliefs about the nature of intelligence, the implicit theory of intelligence survey was designed to measure entity theory (fixed mindset) and incremental theory (growth mindset) beliefs [1]. It involves statements like "your intelligence is something about you that you can't change very much" and asks people to rate their agreement on a Likert scale. Researchers will sometimes create surveys that add "in math" at the beginning of each statement to probe math-specific intelligence beliefs [13]. This is the most context-specific way that psychology researchers have studied beliefs.

Mindset research takes a focus on intelligence beliefs because of seminal studies dating back to the 1970s and 1980s. A typical early mindset study would involve bringing children to a campus psychology lab, exposing them to a challenge, and then measuring how they responded to that challenge [14]. For instance, would a child give up in the face of a challenging logic problem or would they keep trying? At the time, researchers were surprised that children's past performance or grades in school were not actually predictive of how they responded to challenge. Rather, children's beliefs about intelligence were most predictive of their responses to challenge. For instance, some children quickly gave up while other children continued working in the face of failure and difficulty [1]. These studies solidified the applicability of mindset's sociocognitive theoretical framework for understanding children's responses to challenge. Beliefs were treated as binary and fairly stable, but possible to impact. Relationships between beliefs, response to challenge, and goals for learning were explored across many studies.

After showing that children's intelligence beliefs were important to the process of learning in the clinical lab setting, researchers worked on understanding mindset in real-world contexts. This has included work linking mindset to course performance and interventions to change mindset [1,15,16]. Mindset interventions have been designed with the goal of positively impacting student success. Interventions in which students learn about the plasticity of the brain have had remarkable success in improving math grades and college persistence, particularly for populations of students who deal with racial stereotypes about their intelligence and/or who are struggling with grades [11,17-19]. However, very little is understood about the mechanisms by which these interventions seem to work [20]. One of the most recent large mindset intervention studies [19] raised some important questions about mechanism. Somewhat perplexingly, the intervention supported students with lower grades to improve them, however, there was no measurable change in mindset beliefs with these students who had improved their grades. In addition, some of the better performing students did experience mindset belief change but their grades did not improve. Schwartz et al. [20] suggest that social-psychological interventions in mindset are part of "a grand challenge for the field...to develop better instrumentation that can capture relevant behaviors and attitudes over time, and how these vary across context and population." Recent work has attempted large-scale interventions, but there are very few qualitative studies that shed light on mechanism.

Some newer research, although not qualitative in nature, has worked to understand aspects of learning environments with respect to mindset. For instance, researchers have characterized teachers' self-reported instructional practices and their connections with mindset beliefs. In the context of early grade school, it was found that fixed mindsetrelated instructional practices affected student mindset [21]. Likewise, researchers have shown that the type of praise that parents give to children can affect the children's mindsets [22].

\section{B. Mindset and college STEM}

Although mindset is a longstanding area of psychological research, college STEM, particularly college physics, is not a central focus. Only a handful of studies on mindset have been performed in STEM at the university level. The studies that exist focus almost entirely on introductory calculus courses $[13,23]$ with some studies on introductory computer science courses [24,25] and general chemistry [26]. The most detailed study around mindset with students in college physics is a Masters' thesis showing that having a growth mindset correlated with higher Force Concept Inventory gains in a Modeling Instruction context at a large research university [27]. At the time of submission of this paper, there were only sixteen articles in the physics education research (PER)-focused journal within Physical Review that cite a study by Dweck. Only one of these sixteen articles explicitly focuses their research program on mindset [28]. However, the focus of this research is on faculty thinking around graduate admissions and not on students. There is also a nearby study about Ph.D. publication records in physics and chemistry that examines learning orientations [29]. In terms of Schwartz et al.'s 2016 call for more detailed methodologies to understand mechanisms behind mindset, college STEM does not have any such methodologies [20]. Rather, mindset is broadly researched as a factor in student success.

Although not formally framed as work on mindset, some standard physics education research survey tools do probe nearby belief structures. These tools do not explicitly reference the mindset literature. For instance, the Epistemological Beliefs Assessment for Physical Science (EBAPS) has a cluster referred to as "source of ability to learn." This cluster includes Likert scale statements such as, "Someone who doesn't have high natural ability can still learn the material well even in a hard chemistry or physics class." [30]. 
Similarly, the Colorado Learning Attitudes about Science Survey (CLASS) has a few questions under a sense-making or effort cluster such as, "Nearly everyone is capable of understanding physics if they work at it." [31]. The experimental physics version of the CLASS survey (referred to as the E-CLASS) similarly has questions such as, "If I try hard enough I can succeed at doing physics experiments." [32]. Likewise, the Views about Science Survey (VASS) has a learnability cluster that probes whether science is learnable "by anyone willing to make the effort" [33]. Taken together, the sets of questions on these surveys could be considered initial work in understanding mindset in more physics coursespecific contexts. However, clusters or questions related to mindset are not often explicitly studied in research on these surveys. Additionally, researchers have not explicitly mapped out the connections (or lack thereof) between these survey items and mindset's theoretical framework and methodologies.

\section{Mindset research and equity}

Equity-related considerations were not a central aspect of how mindset's foundational constructs were built. Later work has explored connections between race, gender, and mindset [17,23]. However, this work keeps the field's central constructs, such as belief surveys, unchanged.

Our goal in this initial work was to play out mindset's foundational constructs in the more complicated landscape of college physics. Equity considerations did not inform our data collection or analysis methods explicitly. However, we were aware of a number of studies that led us to not ignore moments of student interview talk linked to equity. For instance, work on stereotype threat suggests that the nature of a challenge, like a test, can change based on racial and gender stereotypes being activated [34,35].

Likewise, a number of scholars have called on higher education researchers to consider systemic oppression in their research. For instance, Harper [36] notes that, "rarely were racism and racist institutional norms explicitly named among the range of plausible reasons for racial differences." In addition, McGee and Bentley [37] write about the "troubled success of black women in STEM." In this work, they emphasize that it is key to not ignore, "the toll taken by structural racism, sexism, and discrimination," so that better support structures can be built.

Since these studies did not inform our initial data collection, our data do not focus on experiences of marginalization. However, when such experiences arose in our data as linked to challenge, we did not ignore them. We will walk the reader through key moments where we recognize that marginalization cannot be ignored in how challenge is conceptualized.

Overall, it is important to consider racial and gender identity as more complex than experiences with marginalization. Identity is linked to strengths and "possibility" as well [38]. However, our starting frameworks in this work limit our ability to speak to the complexity of identity.
We will spend a few paragraphs describing how themes of marginalization arose in our analysis as we believe it is an important consideration for others who build on our work.

\section{Context-dependent beliefs in college physics research}

Context-dependent approaches to measuring student mindset in college STEM are currently limited. In 2017, Dweck remarked, "First, we thought people had one mindset or another... we still often assess mindsets that way, but we've discovered over time there are so many triggers in the environment that put any of us into more of a fixed mindset" [39]. Although Dweck herself has called for a less binary approach in how mindset beliefs are studied, research methodologies have not yet caught up. Researchers in college computer science courses have used discipline-general survey measures of mindset [25]. Researchers in college math have developed surveys that ask about math-specific mindset beliefs [13]. We argue for building even more detailed context-specific measures that help us understand the mechanisms behind the role of mindset in college physics.

To build context-dependent mindset measures, we draw upon lessons learned from the physics and science beliefs research literature. Researchers in college physics, for instance, have developed a number of belief surveys (e.g., MPEX, CLASS, etc.) that treat beliefs about physics as fairly stable [31,40]. However, the field has also benefitted from "naturalistic case studies, including open-format interviews" that explore context dependency [41]. Such case studies and interview methodologies have demonstrated ways in which students can display different kinds of beliefs. For instance, Elby and Hammer give the following example of a college physics student [42]:

"When asked how he prepared for his physics test, Louis said that he "studied every word of those homework solutions...I was memorizing the book, too." This response reflects a view of knowledge as something absorbed from an authoritative source. By contrast, talking about his strategies for tutoring other students, Louis said, "what I like to do is build on what they already know instead of introducing a totally new concept," reflecting a view of knowledge as something constructed out of prior knowledge. Louis's variability can be understood as arising from the different contexts activating different resources, in this case resources for understanding the nature of knowledge and how an individual comes to have it"

Researchers have adopted the language of "epistemological resources" to highlight the varied ways that students can reason about the nature of knowledge $[8,42,43]$. Most notably, context-dependent beliefs are not studied through surveys. Rather, student dialogue about one's actions in physics classes are treated as representing certain contextdependent beliefs. We drew on this theoretical framework 
in the data collection design underlying our coding scheme development. To be clear, this is quite different than a standard mindset study's theoretical framework that keeps beliefs and actions separate. Instead, students' descriptions of their actions are taken as indicative of context-dependent beliefs. We will explore some of the limitations of this theoretical framework after presenting our coding schemes.

Two recent studies suggest that coding schemes that allow for seeing variation in mindset-related dialogue hold promise. In prior work, we built a more general mindsetrelated coding scheme to qualitatively examine student interview dialogue across the topics of family stories, $\mathrm{K}-12$ experiences, and college physics [44]. We showed preliminary evidence of variation in mindset-related talk across intelligence beliefs and learning orientations. Likewise, Scherr et al.'s complementary work on physics faculty dialogue shows that qualitative coding approaches do show variation: faculty interviews can contain a mixture of both fixed and growth mindset-aligned statements [28].

\section{DATA COLLECTION METHODOLOGY}

One of the major research questions underling our methodology was, "can we see responses to challenge in college physics that resemble that of the mindset literature?" To address this question, we began with an interview study with students at the end of one year of introductory college physics. Since we were interested in the likelihood of variation in student responses to challenge, an end-ofsemester interview allowed for capturing the broadest range of challenges. In addition, we did not want to assume that we already understood which challenges would be most important. For instance, imagine that we had chosen to focus on exams. In this case, we would have missed a key moment where one student deemed herself not "good at physics" when she compared herself to peers working on classroom problems. We acknowledge in this work that memory is not perfect. Performing end-of-semester interviews will give us somewhat different data than if we had followed students in the moment while they experienced a particular challenge. Nonetheless, our interviews capture students' memories of how they experienced a challenge as well as how they are making sense of those memories during one point at the end of the semester. What we refer to as "response to challenge" is based on memory and later reflection. This is different than a typical mindset literature study that follows response to challenge in the moment. However, given that we were at the beginning of characterizing a complicated terrain, it appeared to us as the best place to start, particularly as this methodology has been fruitful for the context-dependent epistemology work described above.

In this study, we interviewed five students, refined our interview questions, and then interviewed three additional students the following year. A set of colleagues also shared with us one additional interview dataset with thirteen students from another institutional setting. As our goal was to develop methodologies through which we could characterize variation, this set of student interviews gave us enough examples to begin with. Limitations of the sample population will be addressed at the end of this paper. More detail about our interview design and student populations are provided.

\section{A. Interview design}

One-on-one interviews occurred with students at the end of two semesters of introductory college physics. Interviews were roughly $1 \mathrm{~h}$ in length and semistructured. Drawing on the context-dependent epistemological resources theoretical framework $[8,42]$, we designed interview questions that we hypothesized would elicit possible variation in student dialogue about mindset. We crafted questions that we expected would be likely to elicit growthmindset related talk such as, "Do you feel proud of anything in physics?" This question arose from Little's work suggesting that moments of feeling proud frequently co-occurred with seeing one's growth [45]. Likewise, we asked questions like, "Did anything seem hard or impossible at first, in physics, but eventually you were able to understand?" Questions that we expected to elicit more fixed-mindset related talk included, "Some people think that to be good at science or physics it has to come easy to you. On the spectrum of agree to disagree where do you put yourself?" Students would be encouraged to explain their reasoning with examples from college physics. Students' responses to these three questions about feeling proud, hard moments, and what it means to be good at science were the predominant responses analyzed in the coding scheme development presented in this paper.

\section{B. Courses and student populations studied}

As noted, we interviewed five students, refined our questions, and then interviewed three additional students the following year. In our recruitment, we focused on classroom contexts of introductory physics for life sciences courses. This meant that students in these courses were primarily biology students, likely to come in with some trepidation around physics, but also willing to put a lot of work into the class [46]. We also chose a classroom context where these students were most likely to have a positive experience. We chose transformed classrooms with optional project-based components. We hypothesized that this population (with some fear of physics, but willing to work hard and in a transformed environment) was most likely to show variation in mindset-related dialogue and was therefore a good starting place.

Recruitment of students focused on two different introductory physics courses for primarily life sciences majors that emphasized interdisciplinary connections, research-based instructional strategies, and project-based components at a single university. A course transformation effort occurred over the years of our study; thus, one course took place in an 


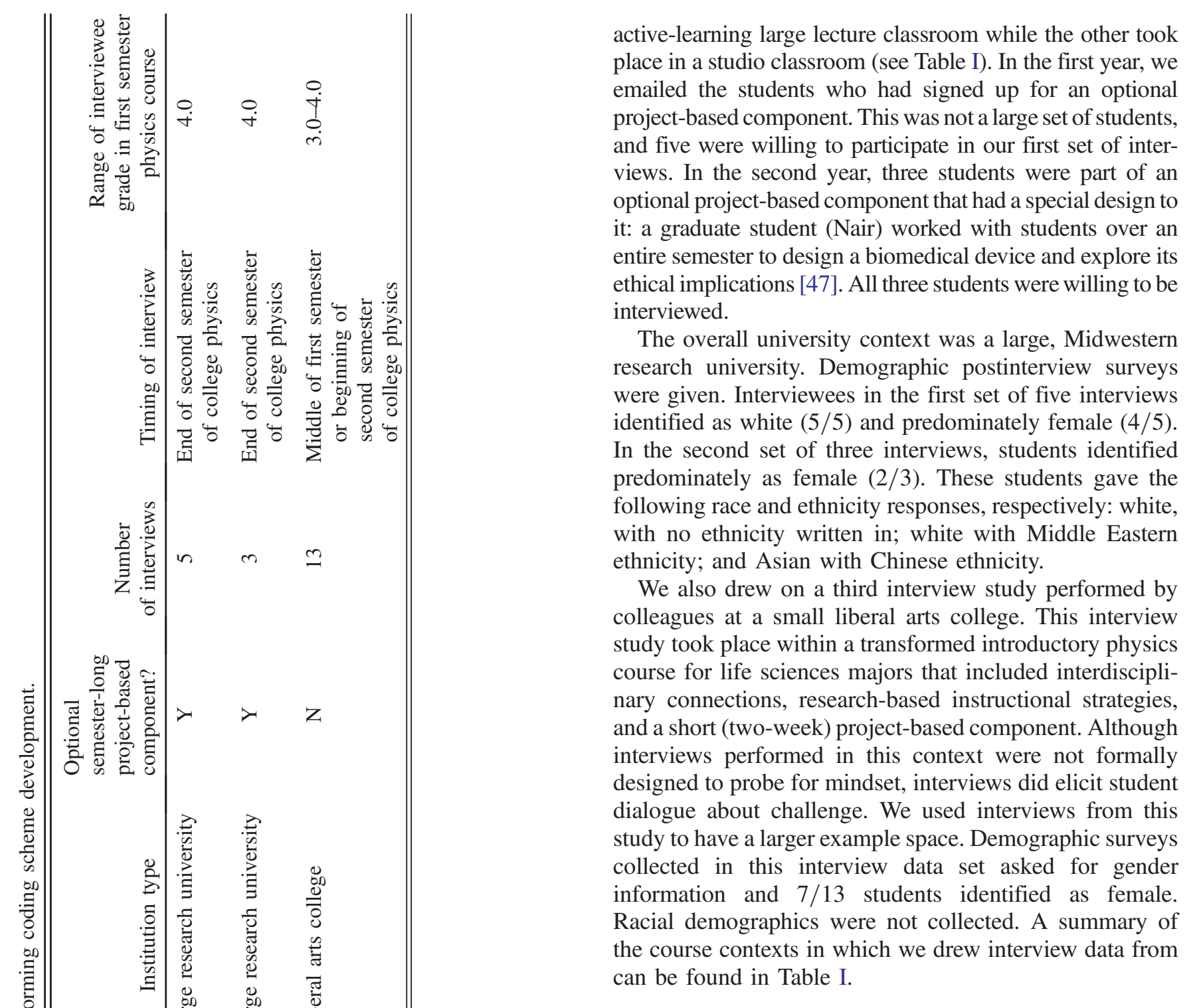

\section{METHODOLOGICAL DEVELOPMENT AND DISCUSSION OVERVIEW}

We will present two distinct coding scheme development processes one after the other: coding for challenge and then coding for response to challenge. First, we will describe a priori codes that we developed through examination of the mindset literature. Then, we will describe the process by which these codes were broken apart, clarified, and added to through examining end-ofsemester student interview data. We will then present the finalized codes.

As a reminder to the reader, this coding scheme was developed as part of a larger research project. In our initial analyses we began with the broad questions, "can we see responses to challenge in college physics that resemble that of the mindset literature?" and "how do students express evidence of challenge and to what extent is such evidence reflective of challenges found in the mindset literature?" These questions were important to answer before being 
able to make progress on understanding mindset-related variation in students' descriptions of their responses to challenges in a college physics course. This paper focuses on these first two research questions and we will discuss each of them after presenting our coding refinement process and finalized codes.

As Engle et al. [48] point out, much research in the learning sciences takes a kind of top-down meets bottom-up approach. Theory informs how one begins when collecting and analyzing data. Keeping one's research questions general allows for discovery of the more unanticipated aspects of the phenomenon that one is studying. One starts with more general questions and those questions are refined in conversation with data. Although we are not performing the kind of fine-grained video analysis found in Engle et al.'s paper, our methodology is consistent with the logic of progressive refinement of hypotheses. In addition, we drew on some best practices for coding scheme development [49]. Our code refining process resembles some elements of the constant comparison method. For instance, Taylor and Bogdan [50] describe the method as one where "the researcher simultaneously codes and analyses data in order to develop concepts; by continually comparing specific incidents in the data, the researcher refines these concepts, identifies their properties, explores their relationships to one another..." In our process we started with a priori codes from the literature, but as we examined the data we were continually asking ourselves-do these data fit with existing codes or do they require a new code? When we were at the final stages of completing the codebook we also carefully considered whether any codes could be collapsed under others. In this way we borrowed methodological techniques from traditions of both constant comparison techniques and also from progressive refinement of hypotheses.

\section{EXAMINING EVIDENCE FOR CHALLENGE}

\section{A. A priori codes grounded in the literature}

One goal of this work is to understand the relationship between kinds of challenge in the mindset literature in comparison to challenges experienced in transformed introductory college physics. Therefore, our starting place for coding challenge was to describe the ways that participants in mindset studies experienced challenge. The mindset literature does not explicitly define challenge because most studies employ tasks that are constructed to be obviously challenging. For instance, kids may be asked to work on problems that are multiple grade levels too high. We surveyed the literature, making our own characterizations of activities typically featured in mindset studies. We characterize challenges found in the mindset literature the following four ways ${ }^{1}$ :

\footnotetext{
${ }^{1}$ The following codes are not mutually exclusive and frequently worked together to make an activity challenging.
}

A priori code

name Description

ISOLATION

Participants were asked to perform challenges on their own [47]. This was challenging in the sense that they could not reach out to their peers if they became stuck on solving a problem.

Confusing or Participants sometimes faced challenges that DENSE involved making sense of densely written material. Dweck describes a study where students had to read a passage that "was written in a muddy and tortuous style" [1].

TASK FAILURE Participants were frequently given conceptual problem-solving tasks that were "too difficult for children their age," resulting in a high probability that they would fail [1].

NEW TASKS Dweck notes that students' "intelligence is certainly on the line in settings where they are being evaluated on a host of new intellectual tasks" [1]. In clinical lab studies it is rare that the challenging aspect of a task was described as having to do with its newness. However, Dweck posited that middle school was a time of new intellectual tasks, and that this newness was an aspect of challenge that students faced.

The goal of our research was to start with a priori codes from the standard psychological literature around mindset. We could then evolve and expand the codes by looking at college physics data. Before looking at our data, we examined the literature to see if there was any research on mindset outside of the standard psychological studies that might expand these notions of challenge. We found only one such study. It highlighted that peer-to-peer interactions may be difficult for students. This study used a grounded theory approach to focus on how students decide to major in computer science [24]. One finding from this study was that students frequently compared themselves to their peers when making decisions about majoring in computer science. Some students attributed their performance to background, while others attributed it to inherent ability. Lewis et al. characterized this dialogue as related to mindset. Students frequently struggled with seeing their peers perform better than them. This caused us to add a new code, an interactional kind of challenge not present in the psychological clinical research studies: PEER COMPARISON-WORSE. We keep peer comparison pulled out of the list of a priori codes, above, to emphasize that peer interaction is not a typical feature of standard mindsetrelated studies.

We started with four a priori evidence of challenge codes from the mindset literature, and expanded to a fifth code based on a qualitative education research study. We expected that we would find additional kinds of challenge when examining college physics interview data. 


\section{B. Selected methodological moments: Shifts to evidence for challenge codes}

After developing our set of a priori codes, members of our team (Little, Humphrey, and Green) examined multiple sets of student interviews. We flagged student dialogue that fit these broad a priori codes as well as anything that seemed related to challenge or students' response to it. We noticed themes that did not fit into an a priori code. We inductively broke out these themes into additional codes. As an example, one additional code that arose in our data had to do with tasks that were tedious in nature. One student described coding as part of a course project as "tedious." This caused us to articulate a new challenge code that we labeled as TeDious. In addition, a number of more interactional challenges arose that had to do with physics course social dynamics not found in individual clinical lab studies.

One important consideration in our coding development process was that we decided not to focus on the magnitude of a challenge. Magnitude is frequently difficult to determine in student dialogue. If one student describes a class as "super hard" and a different student describes it as "kinda hard," this could be a difference in relative magnitude or a difference in two students' cultural speaking styles. Our research uses codes as tags for closer examination and analytic focus. Therefore, this distinction was not key to our research program. For instance, coding for TASK FAILURE could pick up a minor moment such as, "I got that homework problem wrong," as well as, "I failed all of the exams in the class." Likewise, one could imagine the use of TeDious in an easy sense, "It was just a little tedious, but no problem" as well as in a hard sense, "It was so tedious that I gave up and never want to do any more physics." Our coding scheme allows for instances of low magnitude challenge.

Examination of student dialogue also led us to modify details of our a priori codes. For instance, the TASK FAILURE a priori code quickly raised questions in application to our data. Is task failure specific to a student's goals and experiences or something that we as researchers should impose? What grade should count as failing a task? What other markers of failure exist beyond grades? Overall, our approach has been to prioritize how students themselves set and evaluate their own goals. We had moments in our data where a student received a B on an exam, but clearly articulated that their goal was an A. We concluded that setting a personal goal and then failing to meet it should be considered a challenge. In addition, students sometimes describe getting homework problems or project tasks "wrong," typically through an instructor giving them feedback. We considered this to also fall under TASK FAILURE and to be a marker of struggle.

The ISOLATION a priori code evolved in interesting ways through our coding scheme development. At first, we explored tagging whether any activity that a student does alone, like an exam, should pick up a "working alone" code. Indeed, it can be a kind of stressful situation when a student does not have anyone else to talk to if they get stuck, even if exam content is straightforward. We considered using instructor designations about whether course activities were meant to be performed alone or in a group. However, particularly on homework and project-based activities, students frequently move between individual and joint work. This meant that not every course activity had an obvious designation for whether it should be considered individual or joint work. In addition, student interview dialogue was frequently unclear about whether they were working alone or with others. For instance, the phrase, "working on that homework set was so hard!" is not possible to code as individual or joint work. Given the difficulties in coding an activity as individual or collaborative, we abandoned this coding distinction. Another researcher might want to keep track of whether activities are joint or individual ones, but it was not necessary for our research program. The most straightforward aspect of isolation to code was when a student clearly wanted to be working with someone else but was unable to. This is a feature of our finalized coding scheme.

This process of modifying a priori codes in conversation with our data led to an intermediate set of codes with names and descriptions. Our next step was to perform an activity practiced in law [51]. We took student dialogue examples that fit our codes and imagined modifications to those examples. We then asked: would that modified example fit? In other words, we developed hypothetical examples that we felt should fit our codes but that the language of our codes did not currently capture. For instance, let us consider our intermediate DIFFICULT or HARD code. This code's language relied narrowly on adjective use, e.g., "that class was impossible" or "that class was tough." We then imagined more analogical ways to describe something known to be intrinsically difficult, e.g., "that class was like climbing Mount Everest." This caused us to add clarifying language to this code to allow for the use of analogies and not just adjectives.

As a final step to clarifying the language of our codes, we asked a new colleague (Nair) to try to apply the codes to some student data. His use of our codes in practice brought up additional areas where the language of our codes was not entirely clear. We modified the language of our codes to address places of confusion.

As one example, Nair's attempt at using our coding scheme brought up a question about whether our categories were mutually exclusive. For instance, our DifFICULT or HARD code captures fairly general aspects of student language whereas our COMPLEX/CONFUSING/DENSE code tries to specifically tag conceptual difficulties. Consider the following student quotes that involve elements of being 


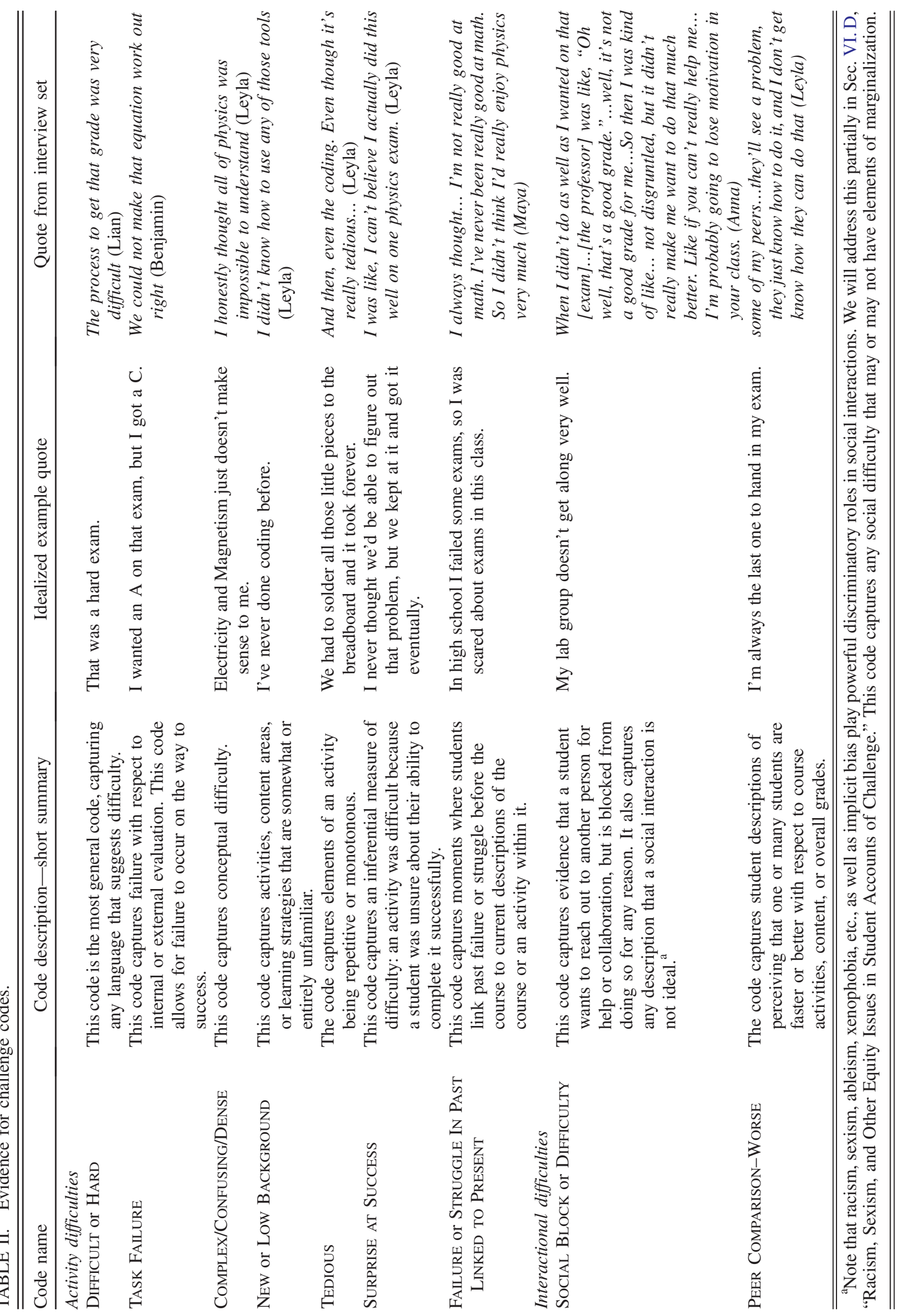


both DifFicult or HARD and COMPLEX/CONFusing/ DENSE. One student noted that physics is "just so hard to understand" and another student described a "really hard concept that I don't get." Ultimately, we decided that our DIFFICULT or HARD code could reasonably act as a broad code that may co-occur with other codes. We made this decision in part because we wanted to capture as much information as possible about student experience with challenge. Our work with Nair led us to modify the DifFICULT or HARD code to include this additional language:

We note that this code is the most "top level" in the sense that there may be many specific versions of it, e.g., "My class was hard" vs "It was hard to understand" vs "It was hard because my group didn't get along." All three of these phrases would get DIFFICULT or HARD as a code; the latter two would pick up COMPLEX/CONFUSING/DENSE and SOCIAL BLOCK or DIFFICULTY in addition. A student might say "This was easy but tedious." In this case, the phrase would only receive a tedious code. However, if a student said "this was hard because it was so tedious" it would receive both.

This process led to the finalized evidence and response codes summarized in this paper and presented in full detail as Supplemental Material [52]. We did not find any codes to be spurious. The five broad areas of challenge from our a priori codes show up, to some extent, in many students' experiences. As long as a code could be seen to plausibly represent some students' experiences in physics courses, it was kept in our codebook.

\section{Evidence for challenge codes overview}

In Table II we present a short summary of each evidence for challenge code, an idealized example, and a real student example from our physics course interviews. These are not the full codebook descriptions. The full codebook descriptions are included as Supplemental Material [52]. We break the codes into two main areas: activity difficulties and interactional difficulties. Note that these codes accept any magnitude of description in student dialogue. For example, "a little bit hard" and "very hard" are all accepted; see Table II.

\section{Racism, sexism, and other equity issues in student accounts of challenge}

When we embarked on this research we were interested in starting with the mindset literature and seeing whether its core constructs played out similarly or differently in college physics. The mindset literature's core studies about challenge do not highlight how equity issues may be wrapped up in what makes an activity challenging. However, when looking at interview data, we quickly recognized that some challenges were related to inequities connected to students' identities. At first, we developed a marginalization-related code to broadly capture student dialogue that dealt with descriptions of ableism, racism, sexism, and other -isms affecting students' interactions with their peers and instructors. We also noticed moments where an activity itself had problematic aspects to it that played a role in marginalization. For instance, one student talked about how physics problems sometimes involve stereotypically masculine activities and how that advantages people who have performed those activities:

Anna: It's hard sometimes, you'll be like, "Well, I've never thrown a football." Like I know it's supposed to go in that arc, but I've never thrown it in that arc, so it's like mine are very much not arc-y. So sometimes things are very hard to visualize in terms of, you know, if I throw it faster what is it going to do? I think that some of the guys who played football or who played football in the yard or whatever, they're like, "Oh, if I hurl it at somebody it's going to take a different path," or something like that.

Upon reflecting on the idea of a marginalization code, however, it stuck out to us as ontologically different than other difficulty codes. Therefore, we do not place student experiences of things like sexism and racism alongside other difficulties. Nonetheless, issues of marginalization clearly factor into STEM learning. It is outside of the scope of this paper to systematically address equity-related issues in students' experiences with challenge. We do not want to treat this issue lightly and believe it necessitates a follow-up paper. In our limitations section, we return to the question of how we might move forward in understanding marginalization when studying mindset. For now, we note a theme that is critically important to understanding student experiences with physics course challenges.

\section{E. Discussion}

\section{Evidence for challenge codes in comparison to the mindset literature}

We now return to our question: to what extent is evidence for challenge in college physics reflective of evidence for challenge found in the mindset literature?

It is not so surprising that there would be differences between the necessarily clear-cut challenges in clinical lab studies and the more complicated landscape of college physics. However, it is critical that, as a field, we have some language to describe our contexts of challenge. This will help us compare our results to one another and better interpret the responses that we see. Our coding scheme relies on student descriptions of challenge rather than researcher-imposed challenges typical of the mindset clinical lab studies. This leads to some evidence for challenge that is distinct from the mindset literature. For instance, in physics class, what constitutes TASK FAILURE is not always straightforward. Perhaps the most straightforward example 
is when a student works on a homework or exam problem and sees that their answer is wrong according to a solutions manual. However, students frequently set personal goals for themselves and can fail at those goals. For instance, a student might set a goal of achieving the grade of an A on an exam and instead receive a B. Thus, our TASK FAILURE code is different from the mindset literature in that it can subjectively include students' own personal descriptions of failure. Similarly, the SURPRISE AT SUCCESS code inherently brings personal history and expectations into one's experience in college physics. SURPRISE AT SUCCESS is frequently linked to a student's prior history with performing poorly in the past.

Interactional difficulty codes reflect a major difference between clinical lab studies with individuals and physics courses where many of the activities are collaborative in nature. Difficulties associated with peer and instructor interactions are lacking in the psychological mindset literature. Mindset studies create an artificial social block where research participants perform tasks alone. Students in transformed physics classes are rarely so isolated.

The Tedious code also reflects a difference between challenges in clinical lab studies and in physics courses. When physics courses emphasize disciplinary skills such as coding, elements of such work can certainly feel tedious. In addition, some of these tasks are repetitive over long timescales. This is different from the constraints placed on clinical lab studies where it is difficult to ask participants, particularly children, to work on problems for more than an hour or two at a time.

Our finalized codes suggest the following result: college physics course challenges are sometimes significantly different from challenges previously described in the mindset literature. This is particularly the case when those challenges are interactional, tedious, and/or related to students' personal goals and histories. In addition, our codes capture a wider range of magnitude of challenge.

\section{Evidence for challenge codes: Mindset threat conditions}

Mindset researchers argue that one only sees bifurcation into fixed and growth behavior in the case that a challenge is threatening enough [1]. Kids with fixed and growth mindset beliefs (as measured by belief surveys) performed similarly on problems that were at their grade level. It was only when faced with problems above their grade level that researchers saw the split into two distinct kinds of response to challenge. We refer to this as a "mindset threat condition." The idea of a mindset threat condition allows researchers to treat all challenges that are threatening enough in the same way theoretically. This proves both methodologically challenging and problematic for theory building in the context of college physics.

First, methodologically, consider an attempt at characterizing a student's description of challenge as meeting some mindset threat condition. College physics does not provide an equivalent for the mindset literature's problems that are significantly beyond grade level. One approach could be to argue for a threshold based on a student's level of worry that they might fail a course or activity. For instance, if a student states they are over fifty percent likely to fail an activity, maybe it is a "mindset threat condition." However, there are cultural dynamics at play in how willing students might be to admit that they are worried they might fail. Still, close attention to culture might allow researchers to argue that students meet some kind of threshold of worry.

Second, a question arises of whether we even should attempt to treat challenges in a binary way. There may be physics course challenges where a student is additionally facing microaggressions from their peers. Imagine that such a student disengages from working on homework with other students. The underlying theory for why a student might respond to a challenge in this way is clearly more related to microaggressions than beliefs about intelligence. Our field must consider ways of paying attention to equity issues in how challenge itself is constructed.

Equity issues are one glaring problem with treating all challenges the same way theoretically. However, additional problems exist. Imagine two students are facing an exam that they both describe as "incredibly hard." One of these two students did poorly on physics exams in high school while the other was more successful. A challenge involving FAILURE OR StRUGGLE IN PAST LinKED TO PRESENT could be experienced quite differently than a challenge that is free from that history. The more that, as researchers, we can be clear about context, the better we will be able to compare the results of our studies.

Given these methodological and theory-related difficulties to a mindset threat condition, we argue that a finer grainsize description of challenge is often warranted to properly interpret students' responses to challenge. Our definition of challenge will necessarily impact how we interpret a student's response to it.

\section{EXAMINING RESPONSE TO CHALLENGE}

\section{A. A priori codes from the literature: Response to challenge}

A large part of the mindset literature is focused on characterizing research participants' responses to challenge. Our research asks, "can we see responses to challenge in college physics that resemble that of the mindset literature?" The mindset literature has clear categories that it classifies as fixed and growth mindset behavior. However, given the differences across our studies, we expected adaptations would be necessary to the mindset literature's original characterizations. The two biggest differences across a typical mindset study and our own include: (i) end-of-semester interviews instead of in-the-moment behavior and (ii) college physics activities 
instead of short problem-solving exercises. Despite these differences, the goal was to stay within the bounds of the mindset literature. More specifically, our finalized "response to challenge" codes stayed within the four broad areas delineated in the mindset literature: effort, strategy, emotion, and self-capability statements [1]. First, we describe our a priori codes.

\section{Effort}

The most straightforward way that the mindset literature tracked response to challenge has to do with giving up versus putting in effort. In developing our coding scheme, we began with a priori response to challenge codes that involved a range of effort: no effort, some effort, and high effort.

\section{Strategy-use}

Another way that the mindset literature tracks response to challenge has to do with employing or changing strategies. For instance, a standard study in the mindset literature involves giving children a few easy problems followed by problems that are much more challenging. In these studies, some children stopped employing strategies that they had previously used on easier problems [49]. Dweck notes that some kids even "taught themselves new and more sophisticated strategies for addressing the new and more difficult problems" [1]. In our starting codes, we looked for problem-solving or metacognitive strategies. We included codes that tracked when students used a particular problem-solving strategy or reflected on their current strategies. We also included a code to tag places where strategies were clearly new or a change from prior work. Starting out, we thought it might be possible to break these codes into more specific ones.

\section{Emotion}

In Dweck's book, she describes "notable negative affect" associated with a helpless response to challenge [1]. She notes that kids "began to express a variety of negative emotions" when they were met with difficulty, including boredom and despair. In the mastery-oriented response to challenge, kids "maintained a positive mood." Dweck notes cheerfulness and statements of excitement such as, "I love a challenge" (pg. 10). Following this literature, we developed a set of a priori emotion codes. These involved general categories of positive and negative emotions as well as specific word flags such as liking, loving, hating, or disliking an activity.

\section{Self-capability}

In the mindset literature, researchers describe a helpless or mastery-oriented response to challenge as involving optimistic or pessimistic self-capability statements [1].
Pessimistic statements would involve doubting one's intelligence, "denigrating" one's abilities, and blaming one's intelligence for failures. Kids would say things like, "I guess I'm not very smart," or, "I'm no good at things like this" [1]. Dweck notes that kids would become pessimistic about future success as well. Using these aspects of the literature we developed a set of a priori codes around positive self-capability and negative self-capability in the present as well as looking toward the future.

Dweck [1] also notes that kids sometimes made selfmotivating or self-monitoring instructions like, "The harder it gets, the harder I need to try," (p. 9). To account for this type of reflective statement, we added one additional a priori code to look for metastatements linking hard work or strategy use to success. In addition, Dweck notes that kids sometimes made "deflection" statements to cover up their poor performance. After performing poorly, some kids told the researcher about their success in other areas [1]. This caused us to create an early deflection code.

In the mindset literature, kids sometimes make selfcapability statements that sound a lot like beliefs. "I guess I'm not very smart" sounds very nearby some of the mindset belief survey items such as, "Your intelligence is something about you that you can't change very much" [1]. However, the mindset literature only measures beliefs through the use of Likert scale survey items. Self-capability statements are characterized as fixed or growth mindset responses to challenge. For the purposes of our coding scheme, we follow the existing literature in paying attention to self-capability statements as a kind of response to challenge.

\section{B. Modifying and adapting response to challenge codes: Selected moments}

The process of modifying and adapting our response to challenge codes followed a similar process to what is described in detail in our evidence for challenge codes methodology discussion. One major difference between the two coding development processes was that the mindset literature has explicitly operationalized growth and fixed mindset responses to challenge. This meant that we started with the more specific a priori codes described above. Then, we followed a similar process to modification that was followed for our evidence for challenge codes. To reiterate: first, we examined student dialogue and this led us to modify details of our a priori codes and arrive at a set of intermediate codes. We then considered hypothetical examples to continue to refine our intermediate codes. Lastly, a colleague (Nair) became familiar with the codes and tried to apply them to some student data. We modified the language of our codes to address places of confusion. This process led to the finalized evidence and response codes presented in this paper.

Some of our codes became more general in nature than those found in the mindset literature. A move toward generality was due to the complexity and idiosyncrasy 
of student dialogue about transformed college physics courses. For instance, in the mindset literature, the kinds of tasks given to participants made it more possible to track the specifics of strategy use. In one study by Deiner and Dweck [53], researchers gave children logic problems. They classified children's strategies as "useful" or "ineffective." Furthermore, within "useful" strategies, researchers had multiple specific strategies such as "hypothesis checking" that were coded and ranked in order of their efficiency for solving problems. This allowed researchers to make statements such as "more than two thirds of [children] showed a clear decline in the level of their problem-solving strategy under failure and over $60 \%$ lapsed into ineffective strategies..." [54]. It is difficult to assign gradation to strategy use in end-of-semester interview data. We took an approach of classifying strategies more generally as either related to a course activity or more interactional and involving reaching out to other people.

The idea of "reaching out to other people" was concretized into a new set of strategy codes that involved interactions with others. We noticed student descriptions of working with other people or attending office hours. When we first noticed examples along these lines, we tagged any moment of interaction, whether it involved peers, tutors, or instructors. However, we ultimately decided to break apart general descriptions of working with peers in a study group from seeking help outside of one's classmates. This became SEEKING Out HelP (not peers) and Working With PEERS. We made this distinction because explicitly seeking out help from people like instructors or TAs appeared to demonstrate an extra level of vulnerability in sharing one's lack of understanding. For instance, Dweck notes that a fixed mindset often results in students working to "hide their deficiencies" [1]. We also recognized that some response to challenge codes could do dual work for us in that they could be considered evidence for challenge. By splitting apart study group-related work from explicitly seeking out help, SeEkING Out Help became a code that could be considered evidence for challenge. Mention of working in a study group could not be as easily considered direct evidence of an activity being challenging. Some students work in study groups whether or not they find the homework challenging.

Drawing on the mindset literature, we originally began with three effort categories: none, some, and high. We quickly realized that almost every activity that students described in their interviews involved at least some effort. We found ourselves applying the "some effort" code so many times that it became a meaningless code. For instance, "I worked on the homework" would be evidence of some effort. This caused us to more clearly articulate what was meant by high effort and we arrived at the HARD Work or SignificAnt Time code.

The final step of bringing in Nair resulted in additional shifts to the language of our codes. Nair pointed out an important distinction in the SELF-CAPABILITY codes. We had both a Negative SMART LABEl code to capture phrases like "I'm bad at physics" and an UNABLE To code to capture phrases like "I can't do this physics problem." The coding team pre-Nair had some instances where the phrase "bad at physics" was coded with both of these labels. Nair pointed out that students would sometimes describe themselves as "bad at physics" while still performing all course activities at a high level. Therefore, we added clarifying language to the NEGATIVE SMART LABEL code to better pull these ideas apart. We also discussed the potential for some overlap in the codes with respect to statements like, "I'm just the kind of person who can't do physics." We added the following language to our NEGATIVE SMART LABEL code:

"If someone is "bad at E\&M" that does not necessarily imply that they cannot do it. This means that this category is not automatically UNABLE TO, but there may be some sentence constructions that pick up both a NeGATIVE SMART and an UNABLE To."

Lastly, we did not find any codes to be spurious. Similar to the coding process for evidence for challenge, the four broad areas of response to challenge from our a priori codes show up, to some extent, in many students' experiences. As long as a code could be seen to plausibly represent some students' experiences in physics courses, it was kept in our codebook.

\section{Some response to challenge codes dually act as evidence of challenge}

In the process of working on our response to challenge codes, we recognized that some codes could be dually considered evidence for challenge. Some of our finalization process involved clarifying some codes so that we could use them in this way. The HARD Work or Significant TIME code, for instance, seemed at face value to convey at least some level of challenge. We looked at each response to challenge code and asked, "could every possible example that this code covers also be considered evidence for challenge?" Some codes clearly fit, while others were more mixed. For instance, the Negative Future code is applied to dialogue where students do not want to engage in more physics courses or disciplinary practices in the future. There are some student quotes picked up by this code that suggest challenge. However, this was not the case with all possible examples covered by the code. For instance, a student might express that they will not take more physics in the future because it is not related enough to their career interests. Members of our research team (Little, Humphrey, and Green) examined each response to challenge code and considered whether all examples covered by the code would count as evidence for challenge. Five of our codes passed this test and these codes can be dually considered to 


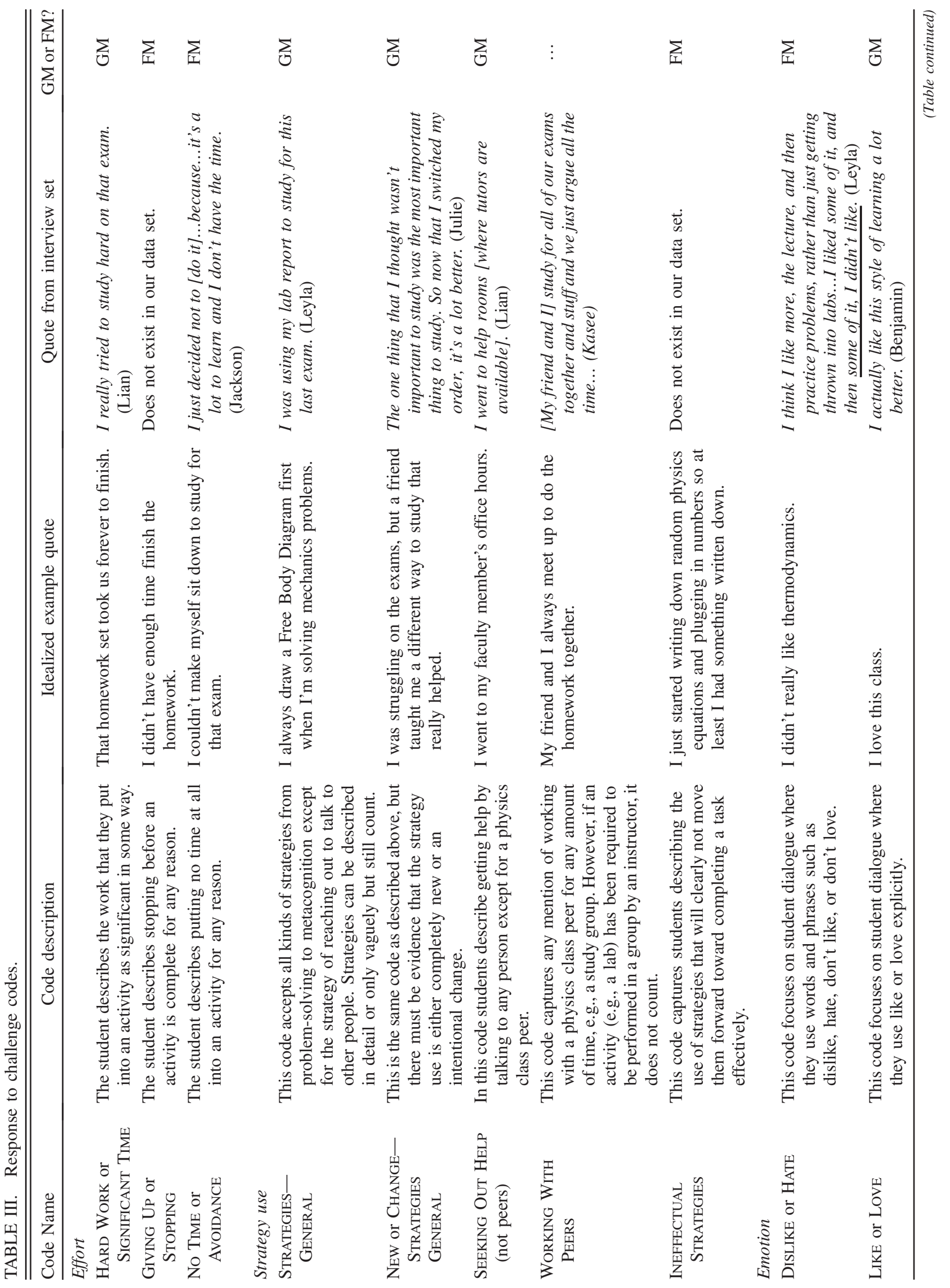




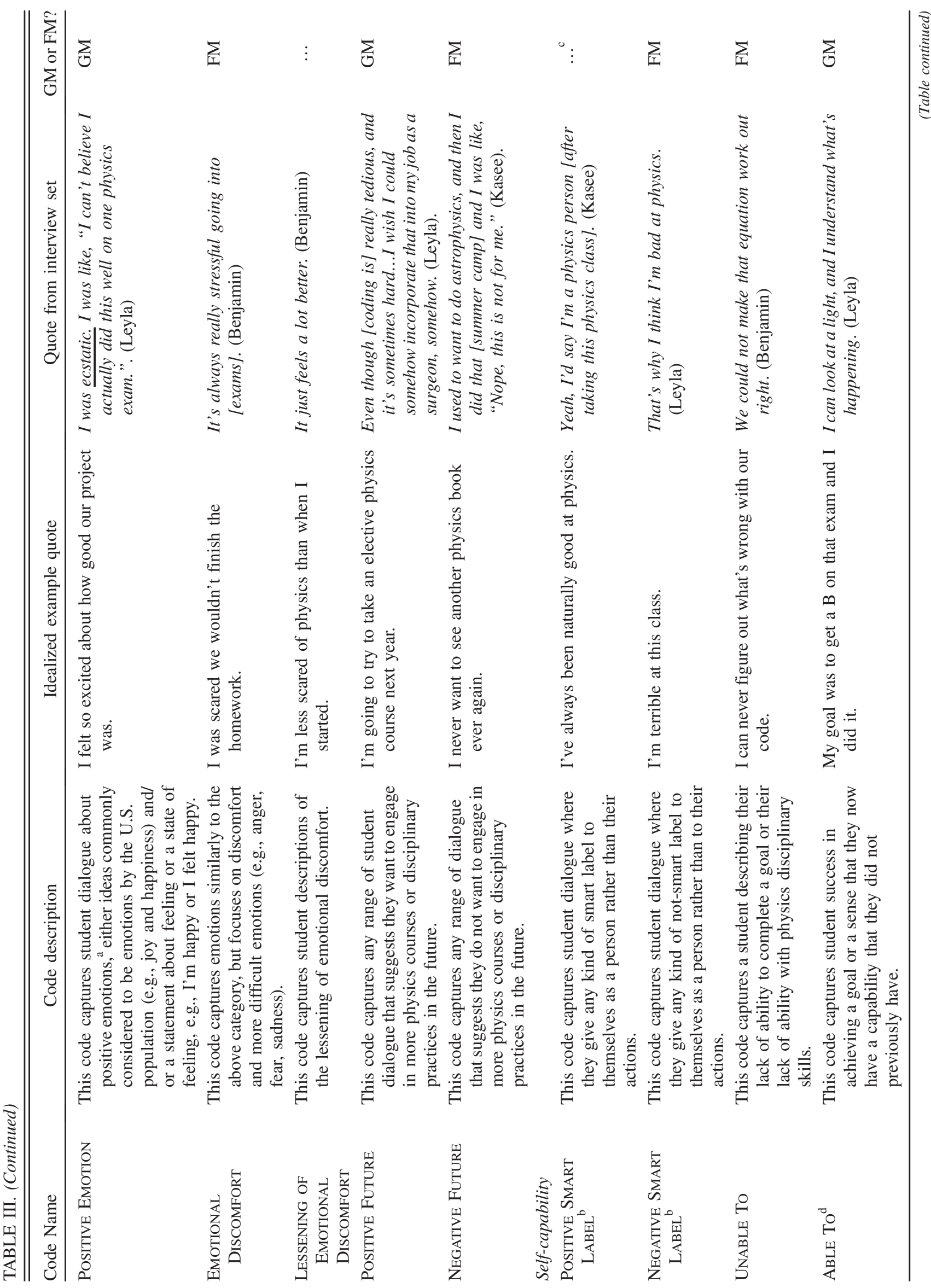




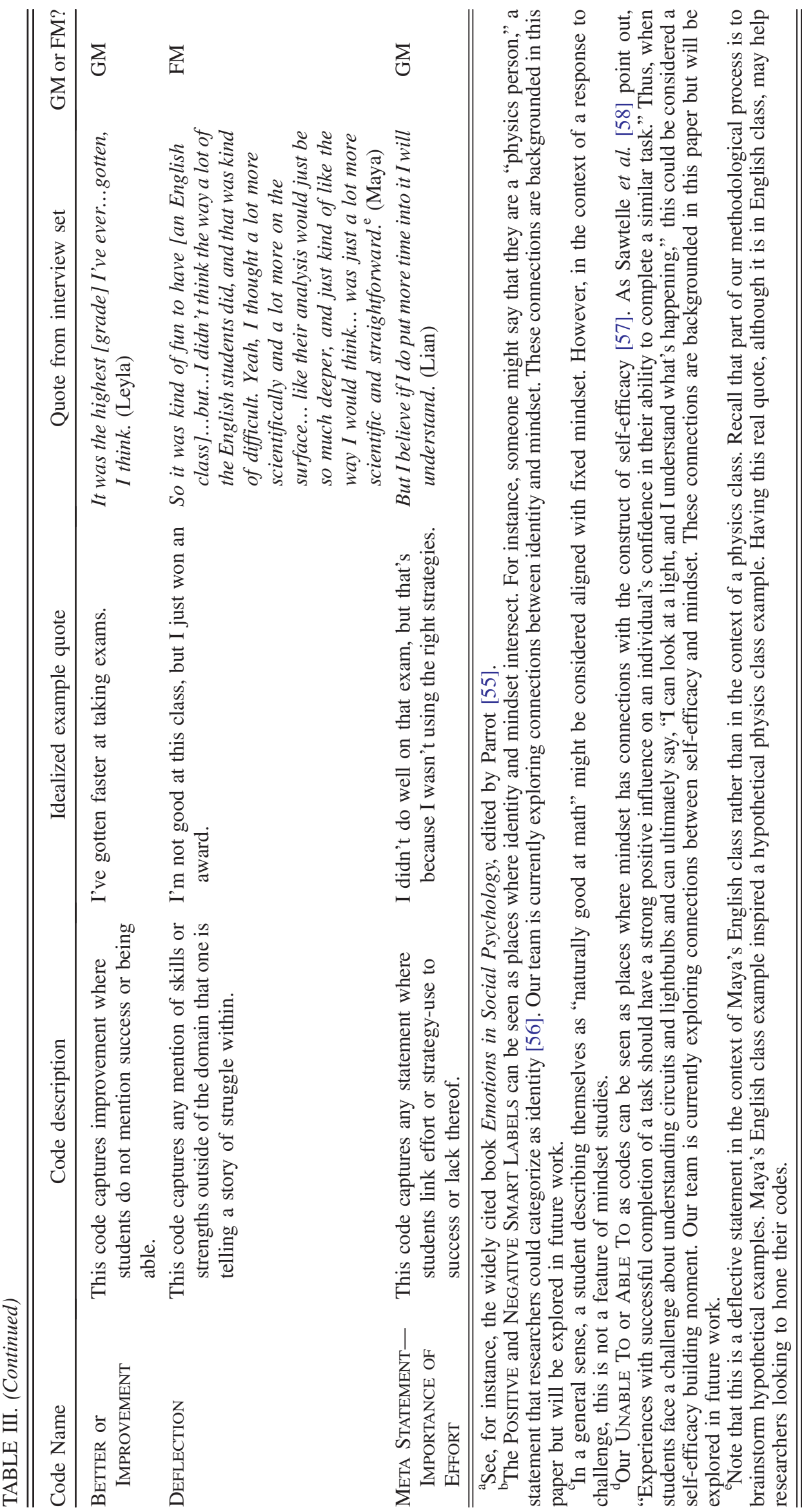


be both evidence for challenge and response to challenge: Hard Work or Significant Time, New or ChangeStrategies General, Seeking Out Help (not peers), Dislike or Hate, and Emotional Discomfort. These dual codes do important work because student dialogue is not always as explicit as "this class was hard."

\section{Response to challenge codes overview}

In Table III we present our response to challenge codes. We provide a short summary of the code, an idealized example, and a real student example, if it exists, from our interviews; see Table III. A quote from our interviews does not exist for two codes. This is due to our process of using realistic hypothetical examples to clarify our codes. The full codebook descriptions are included in the Supplemental Material [52]. We break the codes into four main areas: effort, strategy use, emotion, and self-capability. In the final column, we note whether the code aligns with the mindset literature's description of a growth or fixed mindset response to challenge. We will explore alternative explanations to fixed or growth mindset interpretations in our discussion.

\section{E. Discussion}

\section{Response to challenge codes in comparison to the mindset literature}

We began with the question, "can we see responses to challenge in college physics that resemble that of the mindset literature?" Our coding scheme does allow us to find responses to challenge that broadly fit into the mindset literature's four areas of responses: effort, strategy-use, emotion, and self-capability statements.

Our response to challenge codes were developed in the context of transformed college physics courses. It is not surprising, then, that we capture a somewhat different range of responses than are found in clinical lab studies. We highlight some of the differences between our finalized codes and the mindset literature. We explore the difficulties these differences raise for an interpretation that beliefs about intelligence underly students' responses to challenge. We ask the following: are there some obvious factors that might supersede intelligence beliefs as explanatory? In the following section, we present some of our largest concerns for an intelligence-beliefs-related interpretation of student action.

Effort.-Giving Up or STOPPING in particular raise concerns about a mindset interpretation. For instance, in one of our interviews, a student mentioned strategically putting time into courses. They noted that if they did poorly in one class, "then I'm going to put more of my time into other classes that I could have a potential to get an A." Clinical lab challenges do not have these more difficult decisions embedded in them. Dweck and colleagues do not ignore that people must make hard choices sometimes: "of course, individuals need to be able to gauge when tasks should be avoided or abandoned" [54]. However, most of the studies of challenge in the mindset literature minimize the complexity of this choice. This cannot be ignored in the context of college physics.

Strategy use.-In terms of a mindset interpretation for our strategy-use codes, there are parallels to make with the effort-related codes, above. Dialogue that receives an INEFFECTIVE STRATEGIES code can have explanations beyond beliefs about intelligence. For instance, students may use ineffective strategies if they run out of time on an activity. It could also be the case that students might not believe it is possible to complete an activity or that it is a "threat to their self-esteem" [54]. However, the complexity of students' choices about what to spend their limited time on cannot be ignored here, either.

Emotion.-The emotional landscape becomes more complicated in college physics than in traditional mindset studies. Physics can sometimes be frustrating and we do not expect students to necessarily maintain a "positive mood" [1] at all times during challenges. The challenges we examine are frequently much longer in timescale than a psychology lab activity. A weeks-long project can have moments where students' emotions will reasonably vary. As Jaber and Hammer's work on epistemic affect suggests, children may reasonably experience a wide variety of emotions when engaged in doing science such as, "fascination, curiosity, frustration, boredom, surprise, and so on." [59]. Emotions that might, on their face, seem negative, can ultimately lead to positive outcomes. For instance, "student frustration and struggle" are "necessary features of learning environments that promote ownership." [60]. Therefore, our a priori code from the mindset literature involving negative emotions evolved to a less value-laden final code of EMOTIONAL DISCOMFORT. Is a feeling of boredom arising because of one's beliefs about intelligence or because a science activity is becoming tedious? Both are plausible interpretations of a student expressing boredom. Likewise, is a feeling of fear expressed by a student about their exam arising because of beliefs about intelligence or because of more general testtaking anxiety [61]? It is unclear what the relationship might be between student beliefs and EMOTIONAL DiscomForT, which could be caused by a variety of factors.

Self-capability.-When developing our codes, we pulled apart mention of ability or inability from categorical personal labels to more clearly classify various kinds of self-capability statements. Our "UNABLE To" code raises concerns about a mindset interpretation. We noticed that students sometimes spoke about their inability to succeed or enact a skill, e.g., "we could not make that equation work out right." Mention of inability was frequently transient, followed by accounts of ultimately succeeding. Therefore, 
mention of inability cannot necessarily be interpreted as condemning one's intelligence.

In addition, the Positive SMART LABEL arose from our data and is outside of how the mindset literature categorizes self-capability in response to challenge. If a student said, "I'm naturally good at physics," independent of a challenge, one might consider this statement aligned with fixed mindset. However, in standard mindset studies, recall that kids face a "mindset threat" condition and their behavior bifurcates into two groups: one that stays positive and cheers themselves on and one that denigrates their ability and gives up. There is no behavior that one would label under the Positive SMART LABEL. As an example from one of our data sets, one student described statistics as challenging but noted that it "definitely feels like it's something I'm good at, and it feels pretty intuitive. I joke with people in the class that it's genetic..." According to the mindset literature, the magnitude of challenge is not high enough in moments where we see positive smart labels. However, Positive SMART LABELS are possible with respect to the range of challenges in college physics.

\section{In-the-moment challenge vs end-of-semester interview dialogue}

Much of the mindset literature's characterization of response to challenge occurs in-the-moment in clinical lab studies. Our study involves something quite different: end-of-semester descriptions of challenge. Our interviewees talk about a wider range of content areas and activities. This introduces more complexity into what might be informing a student's response to challenge. We see some of that complexity in our response to challenge codes and our discussion of the interpretation of these codes.

Is it possible to minimize this complexity? Consider narrowing to physics exams for one's focus of study. Would students' responses to challenge look more aligned with the mindset literature in this case? Exams are closest to the kinds of challenges found in the mindset literature. Recall our a priori mindset challenge codes: isolated, complex or confusing, and some likelihood of task failure. If we go even further and focus on a class where a professor writes an exam with a low average score, then the challenge seems particularly analogous to mindset studies. However, even here, in what might be considered the least complex of college physics challenges, complexities arise. What if a student experiences test-taking anxiety [61] or stereotype threat [34]? What if a student has a negative relationship with the faculty member proctoring the exam where that faculty member has expressed doubts about their abilities? This thought experiment suggests that we are "stuck" with complexity if we truly want to understand mechanisms behind the ways that students respond to challenge in college physics. Therefore, we must embrace methods and frameworks that give us footholds to understand the richness of how students experience and respond to challenges in transformed and project-based college physics classrooms.

\section{LIMITATIONS}

Our coding scheme development suggests that individual belief-focused theoretical frameworks for mindset research, even ones that allow for more context-dependent variation, have their limitations. Frequently, one can argue that factors beyond beliefs play a more important role in a student's response to challenge. We posit that existing research on science identity may provide useful theoretical frameworks and methodologies for mindset researchers. For instance, in parallel to studies on identity, one could take a lens of examining classroom activity structures that may make some responses to challenge more or less available to students in certain moments [62-64]. Likewise, research that uses sociocultural approaches to conceptualize identity can speak to the complexity of challenge [38]. Given that some physics faculty consider aspects of physics ability to be innate $[28,32,60]$, examining the classroom and departmental environments that faculty set up should be a focus of study. For instance, Johnson et al. have suggested that faculty messaging that aligns with a growth mindset is one aspect of a departmental culture that is supportive of women of color [65].

Although we noted racism and other forms of marginalization as playing a role in physics course challenges, we have not presented a methodology for taking this into account. In future work, it will be important to represent racial and gender identity as complex, linked to "possibility" as well as linked to structural and interpersonal bias, discrimination, and oppression [38]. Scholars in the context of physics have already laid an important foundation that engages with the complexity of race, gender, and class identity [66-68].

Work on identity helps us see the complexity of challenge. This paper was focused on evidence for challenge. However, there are also positive experiences in students' histories or present interactions that are likely to lead to challenges being more manageable. This will be an important part of future work.

Methodologically, there are a number of considerations for people interested in using our coding scheme quantitatively with larger data sets. Researchers would have to find solutions to difficulties in analytic interpretation that we handle in our more detailed qualitative analyses. As just one example, there are many difficulties in linking up evidence for challenge and response to challenge with one another. Students frequently jump around to various grainsizes when they are discussing a challenging physics class. They might say "The exams in that class were super hard. I also gave up working on the homework." Here, we have evidence for a GIVING UP or STOPPING code with respect to homework and a DIFFICULT or HARD code with respect to exams. This is a methodological consideration other researchers may want to anticipate.

Lastly, our coding scheme was developed with students who skewed toward more successful experiences with college physics. A focus on students who have negative and less 
successful experiences may suggest additional categories of importance in understanding students' responses to challenge.

\section{CONCLUSION}

Very little is actually known about the processes that impact students' responses to challenge in the context of transformed college physics courses. The kinds of challenges found in college physics, particularly those that are interactional, tedious, and related to students' personal goals and histories, have not been the focus of study in the mindset literature. As well, equity issues related to the nature of challenge itself have not been addressed. Broadly, we found that not all challenges are alike and attending to the variety of factors at play in what makes an activity challenging is necessary for making interpretations of student responses to challenge.

What does our coding scheme development and data analysis suggest about ways of moving forward as a field? We have responded to Schwartz et al.'s call for better understanding of "causal forces that could never appear in a laboratory" [20]. For instance, in talking with college physics students who sought to go onto medical school, we saw a complication to mindset lab studies. Students hoping to achieve high grades may not easily give up, even if they ascribe to fixed-mindset aligned intelligence beliefs. As we saw with Leyla at the beginning of this paper, students can describe seemingly-conflicting ideas about working at and becoming capable in physics, while still identifying with "bad at physics" labels. Therefore, we expect college physics courses with predominately life sciences student populations to be particularly complex and insightful terrain with respect to mindset.

The past few years have shown an increased interest in mindset in PER. We believe that the appeal of the construct has to do with an interest in pushing back on prevalent narratives in our field: that physics ability is innate and that one has to be naturally brilliant to be successful [7].

To researchers in the field interested in mindset: our research shows that further development of theoretical frameworks and analytic tools for the context of college physics are in order. Standard studies in the mindset literature that support the link between beliefs and response to challenge are limited in scope and do not centrally address equity concerns. This should give us pause in taking up mindset work uncritically.

To educators and designers in the field: one does not have to wait for additional research to begin pushing back on these brilliance narratives. Indeed, there are many people who have already proposed and implemented course designs that are likely to send the message to students that growth and improvement is possible. As just two of many examples, see Refs. [5,69]. As a long-term goal, we want our research to ultimately link up with the effectiveness of practical design principles. One could imagine research that determines which challenges appear most consequential for students in certain kinds of courses. Then, short surveys could be built around those challenges and used in concert with course design tweaks.

We have provided the first coding scheme that allows researchers to look more closely at student dialogue toward understanding challenges students might face in introductory physics classes. Our coding scheme has broad utility: for those seeking to understand mindset's applicability to college physics and for those attempting to characterize student experiences of challenge more generally. For those seeking to apply a more context-dependent belief framework in interpretation of student dialogue and action, our mindset response codes can aid in such work.

\section{ACKNOWLEDGMENTS}

We acknowledge Lyman Briggs College, the Science and Society@State (S3) Collaborative Grant, and the STEM Gateway Fellowship through the Create4STEM Center at Michigan State University for supporting this work. We thank Ben Geller, Gina Quan, and Dimitri Dounas-Frazer for their thoughtful feedback on this paper. We thank Catherine Crouch, Ben Geller, and Chandra Turpen for sharing interview data that informed our coding scheme development.
[1] C. S. Dweck, Self-theories: Their Role in Motivation, Personality, and Development (Psychology Press, Philadelphia, PA, 2000).

[2] American Association of Physics Teachers, 2018 AAPT Summer Meeting Program, https://www.aapt.org/ Conferences/sm2018/upload/SM18ProgramFinal.pdf, 2018.

[3] D. R. Dounas-Frazer and D. L. Reinholz, Attending to lifelong learning skills through guided reflection in a physics class, Am. J. Phys. 83, 881 (2015).

[4] M. S. Sabella, K. L. Mardis, N. Sanders, and A. Little, The Chi-Sci scholars program: Developing community and challenging racially inequitable measures of success at a minority-serving institution on Chicago's southside, Phys. Teach. 55, 350 (2017).

[5] G. M. Quan, C. A. Turpen, A. Gupta, and E. W. Tanu, Designing a course for peer educators in undergraduate engineering design courses, Proceedings of the American Society of Engineering Education Conference, Paper ID No. 18835 (American Association of Engineering Education (ASEE), Columbus, Ohio, 2017).

[6] SIISP Project: Self-Efficacy Intervention to Improve STEM Performance, https://physics.uncg.edu/siisp/, 2019. 
[7] S. J. Leslie, A. Cimpian, M. Meyer, and E. Freeland, Expectations of brilliance underlie gender distributions across academic disciplines, Science 347, 262 (2015).

[8] D. Hammer and A. Elby, Tapping epistemological resources for learning physics, J. Learn. Sci. 12, 53 (2003).

[9] A. H. Schoenfeld, On paradigms and methods: What do you do when the ones you know don't do what you want them to? Issues in the analysis of data in the form of videotapes, J. Learn. Sci. 2, 179 (1992).

[10] D. Hammer and L. K. Berland, Confusing claims for data: A critique of common practices for presenting qualitative research on learning, J. Learn. Sci. 23, 37 (2014).

[11] D. S. Yeager, D. Paunesku, G. M. Walton, and C. S. Dweck, How can we instill productive mindsets at scale? A review of the evidence and an initial R\&D agenda, White paper prepared for the White House meeting on Excellence in Education: The Importance of Academic Mindsets (2013), https://labs.la.utexas.edu/adrg/files/2013/12/Yeager-et-alRD-agenda-6-10-131.pdf.

[12] D. S. Yeager and C.S. Dweck, Mindsets that promote resilience: When students believe that personal characteristics can be developed, J. Educ. Psychol. 47, 302 (2012).

[13] A. Rattan, C. Good, and C. S. Dweck, "It's ok-Not everyone can be good at math": Instructors with an entity theory comfort (and demotivate) students, J. Exp. Soc. Psychol. 48, 731 (2012).

[14] C.I. Diener and C.S. Dweck, An analysis of learned helplessness: Continuous changes in performance, strategy, and achievement cognitions following failure, J. Pers. Soc. Psychol. 36, 451 (1978).

[15] C.S. Dweck, Mindset: The New Psychology of Success (Random House, New York, New York, 2006).

[16] C. Dweck, Mindsets and math/science achievement, prepared for the Carnegie-IAS Commission on Mathematics and Science Education (2008), https://www.nationalnumeracy .org.uk/sites/default/files/dweck_2008_mindsets_and_mathscience_achievement.pdf.

[17] J. Aronson, C. B. Fried, and C. Good, Reducing the effects of stereotype threat on African American college students by shaping theories of intelligence, J. Exp. Soc. Psychol. 38, 113 (2002).

[18] L. S. Blackwell, K. H. Trzesniewski, and C. S. Dweck, Implicit theories of intelligence predict achievement across an adolescent transition: A longitudinal study and an intervention, Child Development 78, 246 (2007).

[19] D. S. Yeager, C. Romero, D. Paunesku, C. S. Hulleman, B. Schneider, C. Hinojosa, H. Y. Lee, J. O’Brian, K. Flint, J. Trott, D. Greene, G. Walton, and C. S. Dweck, Using design thinking to improve psychological interventions: The case of the growth mindset during the transition to high school, J. Educ. Psychol. 108, 374 (2016).

[20] D. L. Schwartz, K. M. Cheng, S. Salehi, and C. Wieman, The half empty question for socio-cognitive interventions, J. Educ. Psychol. 108, 397 (2016).

[21] D. Park, E. A. Gunderson, E. Tsukayama, S. C. Levine, and S. L. Beilock, Young children's motivational frameworks and math achievement: Relation to teacher-reported instructional practices, but not teacher theory of intelligence, J. Educ. Psychol. 108, 300 (2016).
[22] E. M. Pomerantz and S. G. Kempner, Mothers' daily person and process praise: Implications for children's theory of intelligence and motivation, Dev. Psychol. 49, 2040 (2013).

[23] C. Good, A. Rattan, and C. S. Dweck, Why do women opt out? Sense of belonging and women's representation in mathematics, J. Pers. Soc. Psychol. 102, 700 (2012).

[24] C. M. Lewis, K. Kasuhara, and R. E. Anderson, Deciding to major in computer science: a grounded theory of students' self-assessment of ability, Proceedings of the Seventh International Workshop on Computing Education Research 3 (ACM, New York, 2011).

[25] A. E. Flanigan, M. S. Peteranetz, D. F. Shell, and L. K. Soh, Implicit intelligence beliefs of computer science students: Exploring change across the semester, Contemp. Educ. Psychol. 48, 179 (2017).

[26] H. Grant and C.S. Dweck, Clarifying achievement goals and their impact, J. Pers. Soc. Psychol. 85, 541 (2003).

[27] C. Megowan-Romanowicz, The correlation between student growth mindset and conceptual development in physics, Masters Thesis, Arizona State University, Tempe, AZ, 2011.

[28] R. E. Scherr, M. Plisch, K. E. Gray, G. Potvin, and T. Hodapp, Fixed and growth mindsets in physics graduate admissions, Phys. Rev. Phys. Educ. Res. 13, 020133 (2017).

[29] Z. Hazari, G. Potvin, R. H. Tai, and J. Almarode, For the love of learning science: Connecting learning orientation and career productivity in physics and chemistry, Phys. Rev. ST Phys. Educ. Res. 6, 010107 (2010).

[30] A. Elby, J. Frederiksen, C. Schwarz, and B. White, Epistemological beliefs assessment for physical science (EBAPS), http://www2.physics.umd.edu/ elby/EBAPS/ home.htm.

[31] W. K. Adams, K. K. Perkins, N. S. Podolefsky, M. Dubson, N. D. Finkelstein, and C. E. Wieman, New instrument for measuring student beliefs about physics and learning physics: The Colorado Learning Attitudes about Science Survey, Phys. Rev. ST Phys. Educ. Res. 2, 010101 (2006).

[32] B. M. Zwickl, T. Hirokawa, N. Finkelstein, and H. J. Lewandowski, Epistemology and expectations survey about experimental physics: Development and initial results, Phys. Rev. ST Phys. Educ. Res. 10, 010120 (2014).

[33] I. Halloun and D. Hestenes, Interpreting VASS dimensions and profiles for physics students, Sci. Educ. 7, 553 (1998).

[34] C. M. Steele and J. Aronson, Stereotype threat and the intellectual test performance of African Americans, J. Pers. Soc. Psychol. 69, 797 (1995).

[35] S. J. Spencer, C. M. Steele, and D. M. Quinn, Stereotype threat and women's math performance, J. Exp. Soc. Psychol. 35, 4 (1999).

[36] S. R. Harper, Race without racism: How higher education researchers minimize racist institutional norms, Rev. High. Educ. 36, 9 (2012).

[37] E. O. McGee and L. Bentley, The troubled success of black women in STEM, Cognit. Instr. 35, 265 (2017).

[38] N. I. Nasir, Racialized Identities: Race and Achievement among African American Youth (Stanford University Press, Palo Alto, CA, 2011).

[39] S. D. Sparks, Carol Dweck Wins \$4 Million Prize for Research on 'Growth Mindsets' [blog post, 2017], 
http://blogs.edweek.org/edweek/inside-school-research/ 2017/09/carol_dweck_building_mindset_curriculum.html.

[40] E. F. Redish, J. M. Saul, and R. N. Steinberg, Student expectations in introductory physics, Am. J. Phys. 66, 212 (1998).

[41] D. Hammer and A. Elby, On the form of a personal epistemology, in Personal epistemology: The psychology of beliefs about knowledge and knowing (Lawrence Erlbaum Associates, Inc., Mahwah, New Jersey, 2002).

[42] A. Elby and D. Hammer, Epistemological resources and framing: A cognitive framework for helping teachers interpret and respond to their students' epistemologies, in Personal Epistemology in the Classroom: Theory, Research, and Implications for Practice (Cambridge University Press, Cambridge, United Kingdom, 2010).

[43] D. Hammer, A. Elby, R. E. Scherr, and E. F. Redish, Resources, framing, and transfer, in Transfer of Learning from a Modern Multidisciplinary Perspective (Information Age Publishing, Greenwich, CT, 2005).

[44] A. Little, V. Sawtelle, and B. Humphrey, Mindset in context: Developing new methodologies to study mindset in interview data, 2016 Physics Education Research Conference, Sacramento, CA (American Association of Physics Teachers, New York, 2016), p. 204-207.

[45] A. Little, Proudness: What is it? Why is it important? and How do we design for it in college physics and astronomy education?, in Status: A Report on Women in Astronomy, edited by N. Morrison (American Astronomical Society, Washington, D.C., 2015), Vol 7.

[46] V. Sawtelle and C. Turpen, Leveraging a relationship with biology to expand a relationship with physics, Phys. Rev. Phys. Educ. Res. 12, 010136 (2016).

[47] Vital Signs: Bridging \& Democratizing Physics-Science Society and State Funded Projects 2016-2017, http://s3 .msu.edu/funded-projects-2016-2017/.

[48] R. A. Engle, F. R. Conant, and J. G. Greeno, Progressive refinement of hypotheses in video-supported research, Video Research in the Learning Sciences (Lawrence Erlbaum Associates, Inc., Mahwah, New Jersey, 2007).

[49] M. B. Miles and A. M. Huberman, Qualitative Data Analysis: An Expanded Sourcebook (Sage, Thousand Oaks, CA, 1994).

[50] S. J. Taylor and R. Bogdan, Introduction to Qualitative Research Methods (John Wiley \& Sons, Hoboken, New Jersey, 2016).

[51] E. L. Rissland, Examples in legal reasoning: Legal hypotheticals, in Proceedings of the Eighth International Joint Conference on Artificial Intelligence (International Joint Conferences on Artificial Intelligence Inc., Karlsruhe, 1983), p. 90.

[52] See Supplemental Material at http://link.aps.org/ supplemental/10.1103/PhysRevPhysEducRes.15.010127 for the full codebook.

[53] C.I. Diener and C.S. Dweck, An analysis of learned helplessness: II. The processing of success, J. Pers. Soc. Psychol. 39, 940 (1980).
[54] C. S. Dweck and E. L. Leggett, A social-cognitive approach to motivation and personality, Psychol. Rev. 95, 256 (1988).

[55] Emotions in Social Psychology: Essential Readings, edited by W. G. Parrott (Psychology Press, Philadelphia, PA, 2001).

[56] Z. Hazari, G. Sonnert, P. M. Sadler, and M. C. Shanahan, Connecting high school physics experiences, outcome expectations, physics identity, and physics career choice: A gender study, J. Res. Sci. Teach. 47, 978 (2010).

[57] A. Bandura, Self-efficacy: toward a unifying theory of behavioral change, Psychol. Rev. 84, 191 (1977).

[58] V. Sawtelle, E. Brewe, and L. H. Kramer, Exploring the relationship between self-efficacy and retention in introductory physics, J. Res. Sci. Teach. 49, 1096 (2012).

[59] L.Z. Jaber and D. Hammer, Learning to feel like a scientist, Sci. Educ. 100, 189 (2016).

[60] D. R. Dounas-Frazer and H. J. Lewandowski, Electronics lab instructors' approaches to troubleshooting instruction, Phys. Rev. Phys. Educ. Res. 13, 010102 (2017).

[61] L. A. Brown, E. M. Forman, J. D. Herbert, K. L. Hoffman, and E. K. Yuen, A randomized controlled trial of acceptance-based behavioral therapy and cognitive therapy for test anxiety: a pilot study, Behavior Modification, 35, 31 (2011).

[62] N. Shah, Racial discourse in mathematics and its impact on student learning, identity, and participation (ProQuest Dissertations and Theses database, UMI No. 3593980, 2013).

[63] H. B. Carlone, C. M. Scott, and C. Lowder, Becoming (less) scientific: A longitudinal study of students' identity work from elementary to middle school science, J. Res. Sci. Teach. 51, 836 (2014).

[64] V. Hand and M. Gresalfi, The joint accomplishment of identity, Educ. Psychol. 50, 190 (2015).

[65] A. Johnson, M. Ong, L. T. Ko, J. Smith, and A. Hodari, Common challenges faced by women of color in physics, and actions faculty can take to minimize those challenges, Phys. Teach. 55, 356 (2017).

[66] S. Fries-Britt, J. Johnson, and B. Burt, Black students in physics: The intersection of academic ability, race, gender, and class, in Living at the Intersections: Social Identities and Black Collegians (Information Age Publishing, Charlotte, NC, 2013).

[67] K. Rosa and F. M. Mensah, Educational pathways of Black women physicists: Stories of experiencing and overcoming obstacles in life, Phys. Rev. Phys. Educ. Res. 12, 020113 (2016).

[68] S. Hyater-Adams, C. Fracchiolla, N. Finkelstein, and K. Hinko, A critical look at physics identity: An operationalized framework for examining race and physics identity, Phys. Rev. Phys. Educ. Res. 14, 010132 (2018).

[69] J. Boaler, Mathematical Mindsets: Unleashing Students' Potential through Creative Math, Inspiring Messages and Innovative Teaching (John Wiley \& Sons, San Francisco, CA, 2015). 